\title{
SUPERANDO LAS DICOTOMÍAS: EL QHAPAQ ÑAN COMO EJEMPLO DEL PATRIMONIO COMO PROCESO SOCIAL
}

\author{
OVERCOMING DICHOTOMIES: THE QHAPAQ NAN AS AN EXAMPLE OF \\ HERITAGE AS A SOCIAL PROCESS
}

\author{
Giancarlo Marcone Flores ${ }^{1}$
}

\begin{abstract}
Los estudios sobre patrimonio, durante los últimos años, han insistido en una versión dicotómica en la que la gestión del patrimonio cultural por parte del Estado y la voluntad de las comunidades son contradictorias. Esta concibe al patrimonio cultural como un objeto-discurso, usado con fines hegemónicos, y no como la materialización de las relaciones sociales existentes, por lo que fallan al verlo como un proceso. En este artículo utilizaremos el caso del Qhapaq Nan para ilustrar esta discusión conceptual subyacente a la gestión del patrimonio cultural. Discutiremos cómo recientes publicaciones académicas discuten el tema del Qhapaq Ñan desde la perspectiva de un discurso creado por el Estado que permite a sus autores reclamar, consciente o inconscientemente, ser los interlocutores de las comunidades. Luego, discutiremos una concepción de patrimonio como espacio de negociación social que antecede a los discursos oficiales; y, finalmente, proponemos que la gestión del Qhapaq Nan debe ser entendida como la necesidad de garantizar la participación democrática de todos los actores involucrados, sin imponer visiones -como académicos o gestores patrimoniales-, dejando a los actores tener su propia voz. Así, el Qhapaq Ñan podrá convertirse en un espacio dinámico que facilite la recomposición social y la democratización orientado a políticas de cogestión del mismo.
\end{abstract}

Palabras claves: Qhapaq Ñan, patrimonio, discurso, comunidad, negociación, espacio público.

Heritage studies have recently adopted a dichotomic perspective in which State-sponsored heritage management and the will of communities are contradictory. This approach understands cultural heritage as an object-discourse used for hegemonic purposes, not as the result of the existing social relations, failing thus to understand it as a process. In this article we will use the case of Qhapaq Nan to illustrate this conceptual discussion underlying the management of cultural heritage. We will discuss how recent academic publications discuss the topic of Qhapaq Nan from the perspective of a discourse created by the State that allows its authors to claim to be the interlocutors of the communities, consciously or unconsciously. Then, we will discuss a conception of heritage as a space for social negotiation that precedes official discourses. Finally, we propose that the management of Qhapaq Nan should be understood as the need to ensure the democratic participation of all the actors involved, without imposing views -as academics or heritage managers-, allowing the actors to have their own voice. Thus, the Qhapaq $\tilde{N}$ an can become a dynamic space that facilitates the social recomposition and democratization oriented to co-management policies of the space.

Key words: Qhapaq Nan, heritage, discourse, community, Negotiation, public space.

Hay compañeros de profesión portavoces de su generación, creen que la marginación vive en su barrio, que ilusión.

Loquillo y sus trogloditas

En marzo del año 2017, el Proyecto Qhapaq ÑanSede Nacional co-organizó el III Festival Internacional de Música de Alturas en la localidad de Vilcas Huamán, Ayacucho. En esta ciudad, los edificios prehispánicos, coloniales y contemporáneos se entremezclan cohabitando en una traza urbana irregular, pero cautivante. Esto no ha pasado desapercibido desde el punto de vista patrimonial y las intervenciones allí realizadas se remontan a muchas décadas atrás con los típicos resultados: edificios prehispánicos con conservaciones y restauraciones cuestionadas, y sin un saneamiento legal que permita su gestión sostenible. Como es de imaginarse, en un sitio donde lo

\footnotetext{
${ }^{1}$ Universidad de Ingeniería y Tecnología, Lima, Perú. gmarcone@ utec.edu.pe
}

Recibido: diciembre 2017. Aceptado: junio 2018.

http://dx.doi.org/10.4067/S0717-73562019005002001. Publicado en línea: 23-septiembre-2019. 
nuevo y lo antiguo coexisten y se mezclan, la relación entre patrimonio cultural y la población que lo rodea es conflictiva, tirante y a veces disonante.

El III Festival Internacional de Música de Alturas se realizó con la premisa de fomentar el intercambio entre músicos de diferentes países donde existan montañas. En este marco, se realizaron presentaciones en Lima, Cusco, Huamanga y, a insistencia del proyecto Qhapaq Ñan del Ministerio de Cultura, en Vilcas Huamán. Además, este coincidió con el reconocimiento que le hacía UNESCO a la actriz peruana Magaly Solier como embajadora cultural, por lo que el evento contó con una cierta cobertura mediática de medios nacionales e internacionales.

Las autoridades locales, tanto el alcalde como el presidente de la comunidad de Vilcas Huamán, planearon una serie de eventos para homenajear a las autoridades y funcionarios que veníamos de Lima e inclusive de París. Se planeó realizar el concierto en la plaza principal de la ciudad -al frente de la bella iglesia colonial construida sobre un base de estructuras prehispánicas en estilo Inca- $y$ un acto protocolar en frente del edificio Inca conocido como el Ushnu. En este, existe una pequeña plazoleta, que solo permite un limitado acceso de público, $\mathrm{y}$ es en donde tradicionalmente las autoridades locales realizan sus actividades protocolares (Figura 1).

Algunos de los invitados foráneos no estuvieron de acuerdo con la selección del lugar para el acto protocolar. Estas autoridades intentaron realizarlo en la plaza principal, donde el acto sería más público; por consiguiente, más masivo, esperando quizás un mayor impacto político. Sin embargo, las autoridades locales se negaron, pues el lugar de la plazoleta frente al Ushnu Inca reconstruido es el lugar donde está el simbolismo de la tradición. Es en este donde el alcalde -autoridad moderna- y el presidente de la comunidad -autoridad tradicional- se encuentran, y donde lo local negocia con lo regional y/o lo nacional en términos políticos y sociales.

$\mathrm{Al}$ ser el operario-gestor cultural que estaba mediando entre los invitados de importancia nacional e internacional y los deseos de los líderes locales, esta situación me llevó a reflexionar sobre muchos de los problemas de conceptualización en la gestión del patrimonio cultural. Por ejemplo, cómo el patrimonio cultural es conflictivo en la superposición con el presente, ya que restringe el crecimiento de la ciudad y dificulta su desarrollo urbano; no obstante, permite a las autoridades locales cuestionar e imponer condiciones, aunque sean limitadas a autoridades regionales, nacionales e internacionales.

Del mismo modo, pensaba en la paradoja de que el edificio más intervenido en la ciudad, desde el punto patrimonial -el Ushnu- sea el que conserve el mayor simbolismo para la población. Si "la historia hace a la gente, pero la gente hace la historia" (Ortner 2006:2), entonces el patrimonio lo hace la gente, pero la gente es parcialmente resultado de su interacción con el patrimonio.

Sin embargo, como veremos más adelante, se viene insistiendo en versiones dicotómicas donde el patrimonio y la voluntad de las comunidades son por naturaleza contradictorias. Y esto me llevó a interrogarme: si el patrimonio es una imposición vertical, una creación estatal que desposee a las poblaciones locales, ¿cómo a la vez este se convierte (construye localmente) en los lugares donde justamente se contesta este tipo de acciones hegemónicas por parte del Estado y las élites? ¿Cómo podemos pensar que el patrimonio cultural no es parte del imaginario e identidad de los pobladores peruanos, si han estado influenciados por discursos patrimoniales desde hace más de cien años?

Proponemos que estas contradicciones son resultado de una sobre-simplificación del problema patrimonial en el que la diversidad social e intricados mecanismos sociales son reducidos en una dicotomía Estado-comuneros o élite-comuneros. La construcción de estas dicotomías está facilitada al concebir al patrimonio cultural como un objetodiscurso, una creación usada con fines hegemónicos y no como la materialización de las relaciones sociales existentes. En esta visión, el patrimonio cultural es el objeto del deseo de los actores que luchan por su control y dominio. Si bien estas investigaciones cuestionan la concepción tradicional del patrimonio como un discurso estático dominado por el Estado y los especialistas, fallan en verlo como un proceso.

Algunos autores (p.ej., Gnecco 2017; Jallade 2011) centran su crítica al hecho de que el discurso autorizado sea orientado desde el Estado, un Estado ajeno a lo local y a la gente y que los enajena de su territorio. Este discurso debe ser contestado y son ellos los llamados a hacerlo, asumiendo que ellos sí entienden y tienen la representatividad para hablar por las comunidades, para darle voz a los Andes y a sus habitantes; promoviendo las imágenes de acuerdo a su imaginario y fustigando toda decisión que no se ajuste a sus expectativas de lo que debe ser el comportamiento de la gente que allí vive. Estos autores, se han quedado enganchados en una dicotomía que debería funcionar como parte de un método para aproximarse a los casos, pero que no necesita respetarse a toda costa, y a pesar de los casos. Que esta a su vez impidiendo el desarrollo de maneras creativas de manejar el patrimonio. En la otra cara, existen investigadores que proponen que la forma de entender el patrimonio es de manera dinámica y no estática, ya sea como un "proceso cultural" (Smith 2006) o como el "espacio" donde convergen las diversas dinámicas sociales (Harvey 2001) y donde los actores se encuentran y negocian sus contingencias.

En el presente artículo, pretendemos utilizar el caso del Qhapaq Ñan o red vial andina, para que nos 


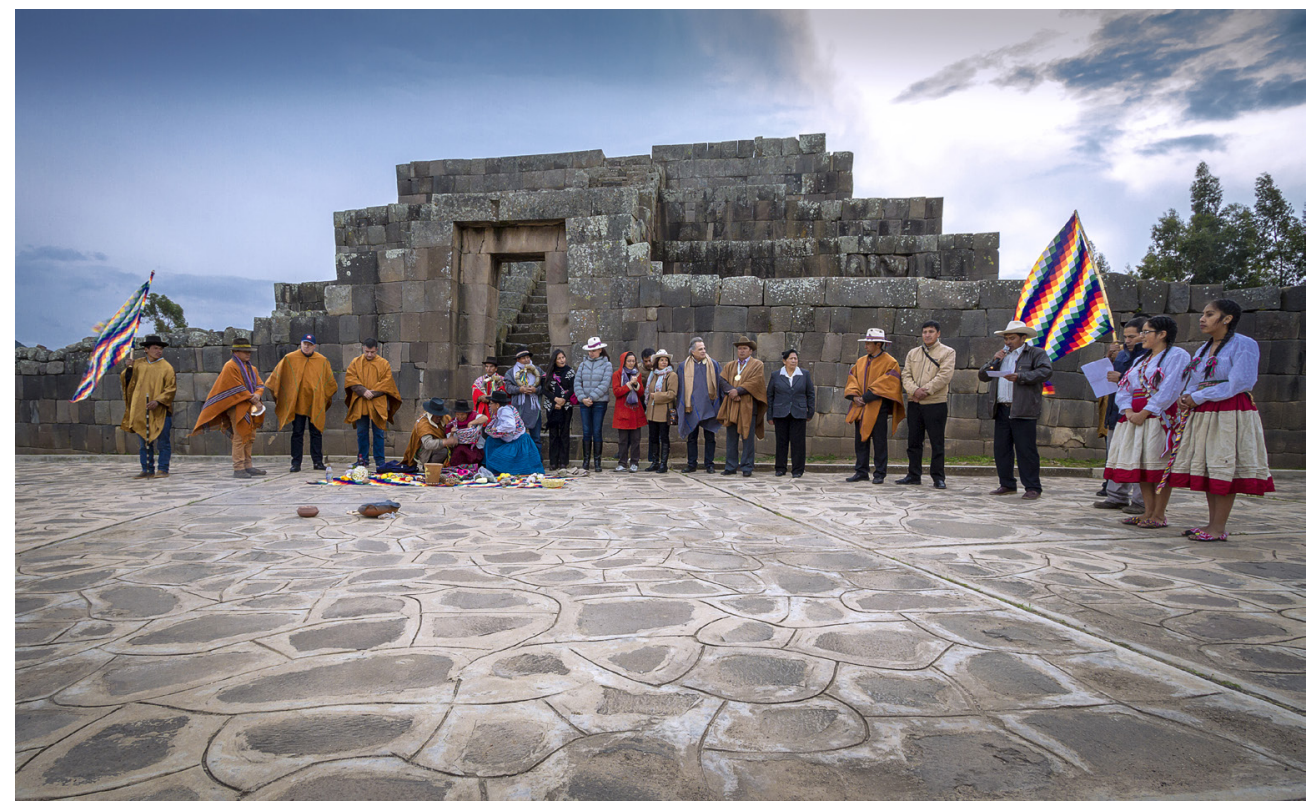

Figura 1. Autoridades participando de un acto protocolar frente a la plazoleta del "Ushnu" de Vilcas Huamán como parte del III Festival Internacional de Música de Alturas en la localidad de Vilcas Huamán, Ayacucho.

Authorities participating in a protocol ceremony in front of the square of the "Ushnu" of Vilcas Huamán as part of the III International Music Festival of the Highlands in the town of Vilcas Huamán, Ayacucho.

ayude a ilustrar esta discusión conceptual subyacente a la gestión del patrimonio cultural. Discutiremos como varias de las últimas publicaciones académicas han discutido el tema del Qhapaq Ñan desde la perspectiva de un discurso creado por el Estado, recreando una dicotomía que es una sobre-simplificación de las dinámicas sociales en juego, pero que les permite a los autores de esas publicaciones reclamar, aunque sea implícitamente, ser los interlocutores de las comunidades.

Luego, utilizando como ejemplo el mismo Qhapaq Ñan o Camino Inca que pasa por el Perú, discutiremos una concepción de patrimonio como espacio de negociación social que antecede a los discursos oficiales. En este marco dinámico, el patrimonio no es una invención sino la materialización de las relaciones y conflictos sociales, uno de los espacios donde los diversos actores de la sociedad se encuentran y actúan.

Finalmente, proponemos que, desde esta perspectiva, la gestión del Qhapaq Ñan debe ser entendida como la necesidad de garantizar la participación democrática de todos los actores involucrados, impidiendo que el camino sea secuestrado de los actores menos poderosos, sin imponer nuestras visiones, soltando poder y autoridad; y, sobre todo, dejando a los actores tener su propia voz. Solo así el Qhapaq Ñan se va a convertir en un espacio dinámico que facilita la recomposición social y la democratización en el sentido más general. Esta diferencia conceptual se refleja en la gestión del patrimonio, mientras unos entienden al patrimonio como objeto de dominación y exclusión, otros lo vemos como un espacio de liberación y cambio social orientado a políticas de cogestión del mismo.

\section{El Patrimonio como Objeto y la Crítica al Discurso Patrimonial Autorizado}

El patrimonio no es en realidad sobre el pasado, sino sobre el presente (Harvey 2001; Lowenthal 1998; Smith 2006) y sobre cómo usamos el pasado para fines del presente. En general, este ha sido usado para la construcción y legitimización de Estados nación y órdenes sociales, con la anuencia de los académicos, en lo que Hernández Asensio (2012) llama "el Pacto Patrimonial" entre las autoridades académicas y las élites estatales.

Esta concepción tradicional del patrimonio no reconoce la multivocalidad, y prioriza los discursos históricos, reconstruidos por académicos que hacen prevalecer las agendas nacionales y discursos estatales sobre las expectativas y opiniones locales. Esta concepción convierte el patrimonio en un objeto inerte, carente de contenido real y usado como objeto en estrategias políticas. 
Pero ya ha sido claramente establecido que esto no es real, que el patrimonio es dinámico y están en constante cambio. Estos cambios se reflejan en la multiplicidad de discursos que se generan y compiten sobre un mismo patrimonio cultural (Waterton 2010:4). Por ello, si bien el patrimonio ha sido usado para exclusión y dominio; también juega un rol en las relaciones de poder que pueden contribuir a cuestionar las jerarquías sociales y generar cambios en las relaciones sociales (Waterton 2010:5).

Patrimonio y poder, en una sociedad, están íntimamente ligados (Harvey 2001; Waterton 2010). Por lo que no es de extrañar que el patrimonio cultural sea parcialmente pensado dentro de los marcos teóricos de las discusiones más generales sobre poder social.

\section{En el Juego de Poder, ¿Quién Habla por Quién?; Patrimonio y la Inserción de la "Comunidad"}

Algunos investigadores proponen que el poder social es la capacidad de los sujetos para transformar activamente sus sociedades, usualmente como resultado de la confrontación entre sus intereses y el de los otros actores sociales (Joseph 2004:4). Estas propuestas están centradas en la contradicción y competencia entre actores como motor de la sociedad, de modo que priorizan los principios de confrontación, contradicción e intencionalidad por parte de ellos. Este tipo de planteamientos han sido muy populares en la arqueología en las últimas décadas por lo que no es de sorprender su influencia en nuestra concepción del patrimonio cultural.

Además, para ellos el patrimonio es una creación de las élites con fines de dominación. Un acto de violencia innata (Gnecco 2017) que cuenta con el aval de lo que Smith (2006) describe como el "discurso autorizado patrimonial". Este discurso de dominación debe ser cuestionado, incorporando las voces de otros actores (en especial comunidades indígenas y otras poblaciones marginadas). Como el patrimonio no existe antes de la formulación por parte del Estado y de las élites, es intrínsecamente asumido que estas poblaciones van a estar invariablemente en contra.

Así, estos autores (p.ej., Hernández Asensio 2012; Jallade 2011) parecen estar en favor del abandono del discurso autorizado tradicional, que habíamos discutido líneas arriba, centrándose, en mi opinión, en el rol del patrimonio como sostén de las relaciones de poder y desigualdad en la sociedad más que en examinar el papel del patrimonio en el funcionamiento y la reproducción de los sistemas sociales.

\section{Recientes críticas sobre el Qhapaq Nan como patrimonio}

Como ejemplo de lo antes mencionado, recientemente, diversos autores (Gnecco 2017; Jallade 2011:2; Korstanje y
García 2007; Losson 2017; Rendón 2017) han escrito sobre el Qhapaq Ñan. Ellos sostienen que este bien patrimonial es un discurso creado desde arriba por los Estados, de manera vertical, con poca o nula participación de las comunidades (Gnecco 2017; Korstanje y García 2007; Losson 2017). Jallade (2011:2) sostiene que la "irrupción de los caminos prehispánicos en el imaginario colectivo" representa una intromisión estatal que desvincula la relación sociedad-naturaleza. Esta patrimonialización que privilegia la monumentalidad (Jallade 2011:2-4), apreciada principalmente por las elites, termina generando la conquista territorial del Estado y el desposeimiento de las comunidades (Jallade 2011:2-6). Además, enajena el tiempo ampliando la brecha pasado-presente (Gnecco 2017) de manera que representa un pasado glorioso sin necesidad de lidiar con un presente de opresión indígena y colonización, limitando el patrimonio a su interés turístico. Jallade (2012:2) señala con acierto que, si bien los documentos oficiales de la preparación del expediente de nominación incluían por lo menos a manera de discurso la idea de la participación de las comunidades, esta no fue aplicada en la práctica.

Losson (2017) se basa en el análisis de Jallade para discutir cómo la prensa de los seis países reportó el proceso de nominación del Qhapaq Nan como patrimonio de la humanidad. Su análisis está centrado en lo parcializado de la información reportada por los medios de comunicación que, al mantener un corte mercantilista, terminaron priorizando contenidos turísticos e invisibilizando a las comunidades locales. Losson nos muestra que lo reportado fue básicamente el discurso oficial, con poca actitud crítica por parte de la prensa y ninguna intención de escuchar voces locales/comunales que Losson asume, en función a lo descrito por Jallade, son voces disonantes (Losson 2017:5). Es sobre todo interesante cómo Losson reconoce tres tipos de actores básicos: los funcionarios estatales, los académicos y las comunidades (Losson 2017). Estas últimas, como él indica, están en permanente lucha por ser reconocidas. Losson (2017) además, llama la atención sobre las conexiones existentes entre patrimonio y Estado. Entonces, ¿quién tiene la autoridad sobre el discurso patrimonial? y ¿quién debería tenerla? Losson (2017:6) nos da una pista cuando al final nos señala que finalmente, pese a los reportes generales, hay una falta de interés en la sociedad en general por el tema patrimonial y que hace que este termine pasando rápidamente de moda.

Para Jallade (2011:2-5) el Qhapaq Ñan no existe a nivel arqueológico para las comunidades; sin embargo, reconoce que algunas secciones del camino tienen uso y significado para las poblaciones locales. Del mismo modo, reconoce que la propuesta y creación de la iniciativa Qhapaq Ñan coincide con un momento particular de la historia peruana, donde esta se estaba reabriendo a los Andes. 
Jallade claramente reconoce que este mismo patrimonio, si bien carecía de valor histórico para las comunidades, estaba presente en el día a día de sus actividades. Así mismo, Losson (2017:2) por un lado reconoce que estos contenidos del día a día son anteriores a los intentos de patrimonialización, planteando un contexto social-político que, a nuestro entender, encontró en el tema del Qhapaq Ñan una válvula de escape social. A pesar de reconocer estas dinámicas anteriores a su patrimonialización, Losson (2017) propone que el hecho de reconocerlo como patrimonio, en lugar de ser válvula de escape o consecuencia de la interacción entre dinámicas locales y generales termina destruyéndolas, ya que es una imposición desde arriba. El contexto social no se ve expresado en el patrimonio, sino que el patrimonio afecta el contenido social cuando al camino se le da contenido histórico. Inclusive, Gnecco (2017:59) reconoce que la interrelación entre patrimonio e historia en el Perú es de muy larga data y que las percepciones del pasado, en especial el Inca, existen recreando a la sociedad, pero a pesar de este reconocimiento sorpresivamente sigue proponiendo que el patrimonio es básicamente una creación vertical estatal.

\section{Lugares Comunes, Lugares Vacíos}

A pesar de estar casi totalmente de acuerdo con las principales críticas expuestas por estos autores sobre el manejo del Qhapaq Ñan como patrimonio, y de reconocer que la participación de la comunidad, en el manejo del Qhapaq Ñan, es más una interesante posibilidad que una realidad, creemos que estos autores están forzando una dicotomía que a nuestro entender no existe más que de manera provisional, como metodología de análisis de caso. Estos autores de manera explícita o implícitamente terminan confundiendo su propio anticolonialismo o anti-hegemonismo, con los intereses de las comunidades, o pensar que, aunque no explícitamente hablan por ellos, su labor critica los hace "aliados" o "acompañantes" de los intereses de las comunidades. Metodológicamente se han quedado atrapados en una dicotomía que funciona como parte de un método para aproximarse a los casos, pero que falla a la hora de promover una gestión del patrimonio realmente democrática.

Como vemos, tanto en los artículos de Jallade (2011:2), Losson (2017) y Gnecco (2017), el patrimonio solo está referido al pasado, no existe para las comunidades presentes. Estas visiones, no reconocen las fuerzas modernas de la sociedad que actúan alrededor del patrimonio cultural como parte del mismo, sino ajenas a los contenidos patrimoniales. Para estos autores, el pasado es usado para robar el presente, estableciendo la dicotomía pasado contra presente, que en el fondo es la dicotomía elites-comuneros, pero también turismo versus identidad, local versus nacional.

Es decir, de nuevo el patrimonio es reducido a su condición de objeto en contingencia. En esta dicotomía, construida por los académicos, se polarizan las posturas. El discurso oficial es criticado, estableciéndose voces alternas sobre el patrimonio, pero que tampoco son las voces de la comunidad. Estas nuevas voces autorizadas critican con la misma dureza cuando estas comunidades se escapan de los ideales de comportamiento de los académicos y no se comportan como ellos (los académicos) quieren. Por ejemplo, Jallade (2011:2-7) se queja de que en Huánuco Pampa la gente se apropia del sitio en la realización de la Fiesta del Sol, la cual en su opinión no representa una verdad histórica; y se queja también de la falta de rigor de las autoridades locales para controlar a la población en su uso de las ruinas (Jallade 2011:2-7). De igual modo, Gnecco (2017:59) fustiga a la celebración del Inti Raymi como expresión del uso de lo incaico de manera referencial para el performance. Además, minimiza desde su posición académica, con un discurso cargado de términos post procesuales, la importancia y significado que tiene ese "performance" a maneralocal; un performance que paraliza la ciudad de Cusco y es clave en su identidad local. La situación no es tan blanca y negra como el artículo de Gnecco pretende exponer. Como Korstanje y García (2007:126) reconocen: las comunidades también participan en la construcción del pasado, así como en el uso del presente. Sin necesidad de la "convocatoria" oficial por parte del Estado, no solo son receptoras, sino agentes patrimoniales activos (ver también Rendon 2017).

Harvey (2014: 578) señala recientemente que, si bien se ha avanzado en promover una visión democrática del patrimonio que cuestione el discurso "autorizado" patrimonial, este todavía está presente, ya sea en la forma de sanciones oficiales o en los imperativos de "alcanzar" categorías particulares de personas. Así, evitar el reconocimiento de la disonancia, tanto en significado, identidad y escala del patrimonio (Harvey 2014:579).

Comodecíamos anteriormente, las posturas expuestas líneas arriba terminan recreando una sobre simplificación social donde el patrimonio es el objeto del deseo y luchas de Estado/elites versus los comuneros, donde se critica la autoridad del Estado para desacreditarlo; y, a la vez estas críticas reclaman de manera explícita o implícita ser los portavoces de las comunidades, o al menos sus aliados y acompañantes, pero sin tomar en cuenta realmente sus opiniones. Así, estas prácticas terminan por cuestionar los discursos hegemónicos solo en la superficie. Además, la contestación de 
estos discursos hegemónicos continúa en los espacios académicos con poca referencia a espacios reales donde los grupos interactúan. Estas interacciones son complejas y ambivalentes como lo es la relación entre el patrimonio y la población.

En nuestra experiencia, tampoco la comunidad es un conjunto uniforme. El patrimonio también está sujeto a tensiones sociales, étnicas y de género -a nivel local- dentro de lo que llamaríamos una comunidad (Perkin 2010; Rendón 2017). Del mismo modo, todas las comunidades no piensan igual, ni tienen los mismos mecanismos sociales y muchos menos los mismos objetivos. Es justamente esa diversidad social lo que nosotros consideramos es la verdadera riqueza del Qhapaq Ñan. Así, la comunidad de Huaytará, en Huancavelica, es una comunidad que trabaja en un entorno empresarial y que incluso es dueña de su propio Hotel en el pueblo principal. Por otro lado, la comunidad de Aguamiro, colindante con el sitio de Huánuco Pampa, en Huánuco, si bien tiene las tierras colindantes con el sitio viven en su mayoría en el Pueblo de la Unión. En ambos casos las expectativas y relación con el patrimonio son diferentes (Figura 2).

\section{El Patrimonio como Relación Contextual: El Qhapaq Ñan como Espacio Público y Negociación Social}

Como decíamos líneas antes, hay una manera alterna de pensar el patrimonio. En esta, el patrimonio no es un objeto-discurso (en el sentido que el discurso político crea un patrimonio inexistente con anterioridad, este discurso está centrado en las capacidades muebles o inmuebles del patrimonio y no en sus significados para la gente alrededor del mismo). El patrimonio es la expresión de relaciones sociales al interior y entre grupos. Estas propuestas están imbuidas dentro de los marcos conceptuales de la teoría social. Además, el patrimonio es pensado desde marcos de interpretación dinámicos, ya sea como proceso (Smith 2006), verbo (Waterton 2010) y/o como espacio público (Harvey 2001) donde las dinámicas sociales se despliegan. Visto así, el patrimonio es el resultado de diversas tensiones sociales que van desde la tensión entre modernidad y tradición hasta la discusión entre lo que como sociedad recordamos y olvidamos (Smith 2006), pasando por la tensión entre identidades nacional, regional y local (en el caso del Qhapaq Nan, inclusive internacional). Estas relaciones son negociadas y contestadas permanentemente. Es así que, como en el caso de Vilcas Huamán discutido al inicio, el patrimonio tiene la posibilidad de convertirse en capital social, económico y político.
Es este capital el que los diversos actores utilizan en su relación entre ellos.

El patrimonio cultural, no es creado por nadie, tampoco es historia, pues existe antes y más allá de su dimensión histórica. No pertenece a ningún actor en específico, sino que las relaciones de poder alrededor de él se dan a partir de la interacción de los actores con el espacio físico y social que ocupa el sitio. Donde el poder emana de la relación dialéctica entre las oportunidades e intenciones de los actores sociales y la restricción de las estructuras sociales (tradiciones, las instituciones u otros actores imponen sobre ellas) (Giddens 1984; Miller y Tilley 1984; Ortner 2006).

Si el patrimonio es poder social, las relaciones sociales que suceden sobre o alrededor del patrimonio se deben entender en relación con el contexto más amplio de la sociedad en su conjunto, como estas relaciones traspasan o engranan las diferentes escalas y grupos sociales. La dimensión local no es ajena a la dimensión regional, nacional e internacional, no es posible entender una sin la otra, ya que están mutuamente constituidas (Ortner 2006).

Como defendíamos líneas arriba, la contraposición entre población local, como intrínsecamente en desacuerdo con las agendas nacionales, es claramente una sobre simplificación. Existen sitios declarados como parte del Qhapaq Nan, como el Santuario de Pachacamac que por su ubicación, importancia y presencia icónica -tiene más de 100 años como patrimonio- sobrepasa el ámbito local. Entonces, el problema no es reconocer este ámbito supralocal del patrimonio, sino sobreponerlo a los elementos locales. Es por eso que una de las las dimensiones del patrimonio a explorar es la capacidad de enlazar estos contextos locales con temas y problemáticas nacionales. Y este entrelazamiento de por sí constituye un importante capital social para poblaciones locales, incrementando su participación en esferas de interacción social a las que de otra manera no tendrían acceso.

Por ejemplo, en la zona de Puno, el segmento de Qhapaq Nan que, viniendo del Cusco, atraviesa la región hasta la frontera con Bolivia está siendo usado de eje articulador de iniciativas de turismo rural comunitario tanto en Perú como en Bolivia. En este caso, políticas nacionales y agendas binacionales han sido montadas sobre el patrimonio cultural para generar modelos de negocios de carácter local. La actitud de la población es todavía contemplativa, pero existe conciencia de los posibles beneficios a nivel local, por lo que de ambos lados de la frontera son receptivos a las iniciativas. Éstas a su vez contribuyen a mejorar las relaciones binacionales. En este caso, la 


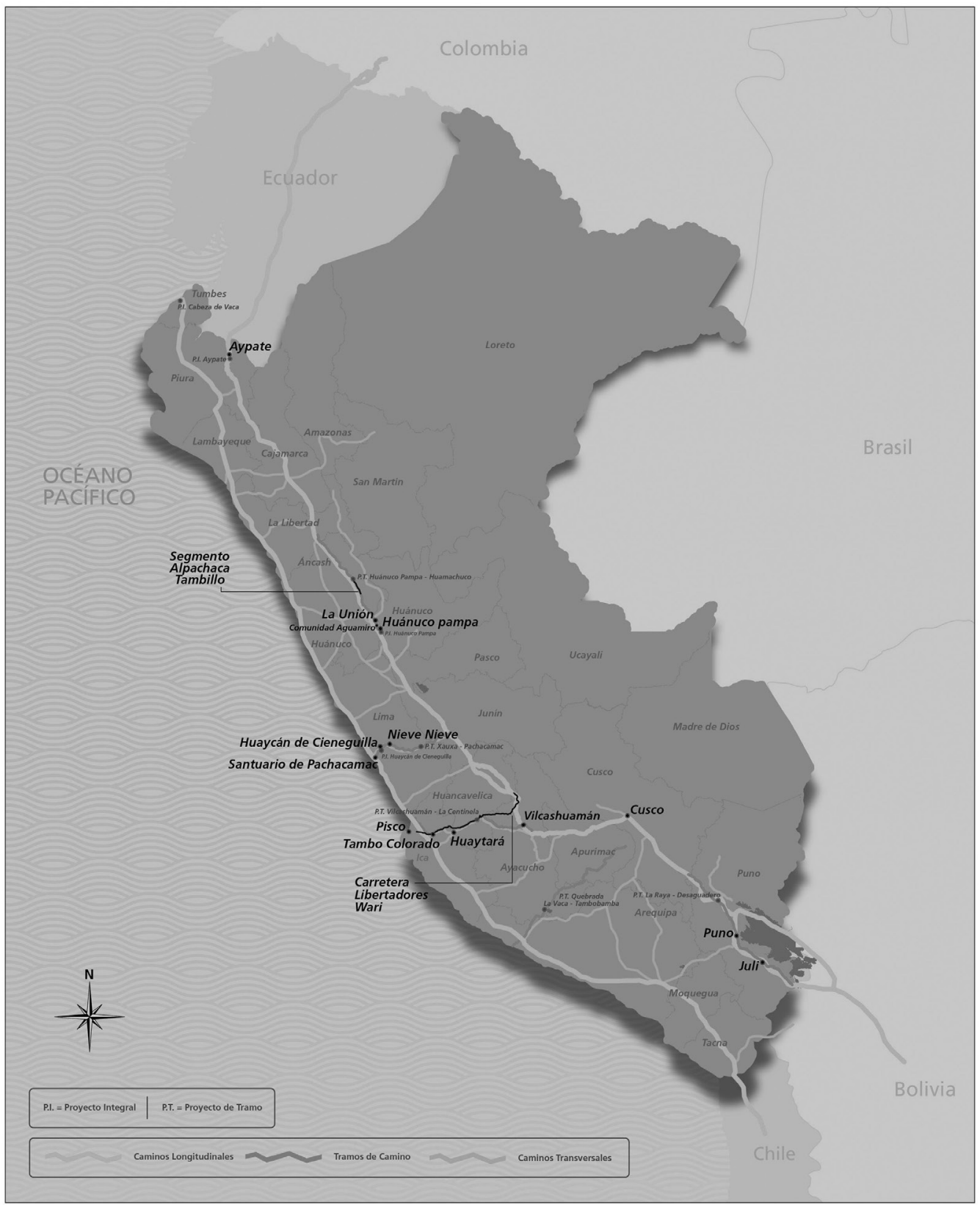

Figura 2. Mapa de los lugares mencionados en el artículo.

Map of the places mentioned in the article.

agenda y los deseos de las comunidades en el área parecen coincidir con las propuestas estatales sirviendo el camino como potencial integrador de estos dos niveles sociales.

Sin embargo, es difícil generalizar. Por ejemplo, en el sitio de Aypate, en Piura, cerca de la frontera entre Perú y Ecuador, la población circúndate se ha encontrado aislada de la presencia del Estado por años. Las agendas locales y estatales parecen estar en conflicto toda vez que las comunidades tratan de defender sus tierras del avance de proyectos extractivos. La comunicación entre comunidades y el Estado 
central se viene restableciendo de a pocos mediante el patrimonio. Los comuneros ven como una oportunidad de legitimar su presencia en la región, pues el hecho de que Aypate haya sido nombrado como Patrimonio Universal por la UNESCO ha obligado a otros sectores del Estado peruano a mirar hacia la zona. Así, la gestión local de un monumento puede influenciar y cambiar las agendas nacionales.

El Qhapaq Ñan está influenciando directamente las dinámicas geopolíticas de la región, tanto a nivel supra nacional, nacional, así como a nivel local. El Qhapaq Ñan, que fue en el pasado una compleja red de caminos pedestres principales y secundarios, usados antes y después de los Incas, presenta uso y vigencia en el presente. No solo porque algunos de estos caminos se usan como vía de comunicación incluso hoy, sino porque el ordenamiento del territorio claramente a seguido los trazos marcados por el camino en el paisaje.

Por ejemplo, el tramo Vilcas Huamán hasta La Centinela fue una ruta de acceso a la costa desde el centro Inca intermedio de Vilcas Huamán. Este tramo de camino se convierte en época Inca en una de las principales vías de comunicación entre la Costa y la Sierra. Es este mismo camino que luego es utilizado por los conquistadores para arribar al Cusco, así como durante sus peleas. $\mathrm{La}$ información muestra claramente como las tropas españolas, tanto de Diego de Almagro como las de Francisco Pizarro, hacen fuerte en sitios como Huaytará o Tambo Colorado, que eran parte de las estancias construidas por los incas a lo largo del segmento (Cieza de León 1985:6). Pero no solo en el inicio de la colonia se continúa usando estos ejes de comunicación y movimiento. El segmento en cuestión coincide parcialmente con la ruta que siguen las tropas libertadoras que arriban a Pisco y suben hacia la sierra central en 1810. Hoy por hoy, este eje sigue siendo una de las principales vías de comunicación de la costa a la sierra, gracias a la moderna carretera "Libertadores-Wari", una de las carretas principales del Perú en la actualidad.

\section{Superando la dicotomía}

Como es aceptado, las sociedades del pasado y el legado histórico han sido usados para construir discursos inmersos en procesos de dominación, exclusión social y nacionalismo. En el caso peruano, han sido usados para construir un modelo de modernidad ligado a la construcción del Estado-Nación.

...El indio es, pues, aceptado en tanto paisaje y gloria lejana. Es "sabio" si es pasado y abstracto, como Manco Cápac. Es bruto o "estólido", e "impuro" y "vándalo", si es presente, ... Apelar a la memoria de los Incas para despreciar y segregar al indio. Las raíces de la más conservadora retórica indigenista criolla, cuyos ecos son perceptibles en nuestros días, deben buscarse aquí (Méndez 1996:19).

Entonces, la idea de un patrimonio neutro o ajeno a las comunidades en el Perú es una ilusión conceptual. O pensar que las comunidades son solo reactivas es de mucha condescendencia. Inclusive, en el camino más recóndito del Qhapaq Ñan existe una población que ha sido excluida y dominada a través de los discursos políticos basados en la historia. No es posible pensar el Perú sin repensar en nuestra relación con los símbolos del pasado, no es posible desplomar estos discursos hegemónicos construidos sobre el patrimonio negando su existencia.

Es que el patrimonio cultural no es una verdad histórica, sino la materialización de una serie de relaciones sociales que se dan en el presente (Smith 2006). No es neutro, sino que está cargado de significados y estos no están contenidos en los objetos, edificios o danzas, sino en las historias que sobre ellas cuenten los diversos actores y las maneras en que se relacionan con él (Harvey 2001). Esta diversidad y variabilidad de discursos ligados a los contextos sociales cambiantes generan que tengamos tantos discursos como actores tenemos; además, estos cambian con el tiempo en la medida que los actores y las relaciones entre ellos cambien.

Por lo tanto, es imposible reducir el patrimonio a la dicotomía elites-comuneros o local-nacional. El patrimonio, al igual que la mayoría de los contextos sociales, se vuelve en sí un espacio contencioso. Es contencioso porque su control o dominio tiene repercusiones reales y tangibles que se convierten en capital social; inclusive, económico. El grado de control que se tenga sobre el patrimonio se vuelve poder y hasta define territorios que afectan tanto las relaciones entre los grupos que actúan alrededor del patrimonio, como al interior de los mismos grupos (Perkin 2010; Waterton 2010). Pero donde no hay actores exclusivamente receptivos, sino que todos se encuentran actuando de acuerdo a sus propias expectativas sobre el mismo.

El hecho de estar al medio de un espacio social contencioso hace que el patrimonio sea un medio de comunicación poderoso. Usualmente usado para perpetuar discursos hegemónicos, también puede ser usado para fomentar cambios de mentalidades que generen cambios sociales. No obstante, en el Perú el patrimonio ha sido usado para la creación de una identidad nacional y negación de las identidades locales. Así como el Qhapaq Ñan, llevado desde un 
discurso patrimonialista clásico, puede servir para desposeer territorio y quebrar conceptualmente a los pobladores de su pasado, de su territorio, dando la impresión de estar prestados en el presente (Gnecco 2017; Jallade 2011:2); también, es cierto que el uso continuo y real de estas rutas hasta el presente es resultado de la mediación que hace el camino sobre el paisaje, que a su vez se vuelve uno de los factores que dan forma al proceso histórico peruano. Una vez construido el camino, este ha transformado el paisaje y el territorio, teniendo un rol activo en la composición del Perú de nuestros días. Es esta relación camino-paisaje la que puede terminar reconciliando historia y territorio.

Como se ha mencionado, el patrimonio ha sido usado para crear discursos hegemónicos en el Perú. Se han creado discursos de segregación y exclusión sobre los que nace la nación peruana (Marcone 2011); y, creemos que estos discursos solo podrán ser cuestionados desde el mismo patrimonio. Si el discurso hegemónico quiebra la historia, haciendo que el proceso español de conquista sea tan diferente de la naturaleza indígena que termina legitimando a los criollos e invisibilizando los indígenas de nuestra historia; el Qhapaq Ñan más bien puede contar la otra historia, una historia que cuestiona esta narrativa oficial insertada en el imaginario colectivo del peruano. El camino cuenta una historia de continuidad, donde los eventos históricos están ligados al paisaje y al territorio; y, si están ligados al paisaje y al territorio, no pueden ser ajenos a los procesos locales. Entonces, los quiebres históricos no fueron tales. Este reconocimiento cuestiona la construcción criolla de la nación y muestra como un proyecto patrimonial, que es acusado de ser impuesto desde arriba hacia abajo, termina cuestionando los discursos nacionales hegemónicos más profundos.

Muchas veces se piensa que la iniciativa Qhapaq Nan, por ser un proyecto patrimonial propuesto "desde arriba", tiene que estar en directa contradicción con los intereses de la población. El asumido escondido es que, al no ser una idea original de la población, esta no se va a apropiar del proyecto ni del patrimonio. Se asume que la iniciativa gubernamental va en directo conflicto con las agendas locales. Sin embargo, aún desde un proyecto gubernamental hay espacio para alimentar las historias e identidades locales. No toda acción gubernamental es negativa para la población o no aceptada. Por ejemplo, la zonificación participativa del camino, impulsada por el proyecto gubernamental Qhapaq Ñan, es el modelo que viene dando resultados en la línea de alcanzar una cogestión de los monumentos. En esta, se presenta una propuesta para zonificar en conjunto las secciones del camino con las comunidades, donde se compromete a la población a la demarcación de su propio territorio
(Proyecto Qhapaq Ñan 2014). Más allá de los intereses puntuales de delimitación del Estado, la población usa esta zonificación para restringir el acceso y defender la tierra de la intromisión de las minas y/o actividades de corte productivo. A veces, dependiendo de su contexto local y conveniencia, los límites del área protegida se establecen -a pedido de las poblaciones- en la cima de las colinas, poniendo carga restrictiva sobre el terreno evitando así la expansión minera, este es el caso de la zonificación del camino en el segmento AlpachacaTambillo o la zona del Pariacaca en el tramo XauxaPachacamac. $\mathrm{O}$, a veces, el caso es totalmente contrario: la zonificación participativa ha permitido a las comunidades defender el área agrícola contra la intervención patrimonial, restringiendo el área protegida al mínimo posible, en orden de mantener la integridad de su tierra de cultivos. Esta gestión participativa fue ganadora del Premio a las Buenas Prácticas en el Estado peruano en el año 2017.

La idea de una gestión participativa del patrimonio implica justamente la pérdida de autoridad de parte de los académicos y gestores culturales, dando cabida a los intereses locales; inclusive si van en contra de nuestra "autoridad" como gestores. Por ejemplo, la reciente delimitación del complejo de Vilcas Huamán, donde coexisten estructuras pre-incas, coloniales y modernas siempre fue materia de contención entre el Estado y la población. Esta delimitación quedó trunca por varios años, deteniendo proyectos urbanos y saneamientos físico-legales. Así, el patrimonio se convirtió en un impedimento, desposeía y marginaba a una población que buscaba la modernidad. Esta situación seguiría eternamente si no fuera por la aplicación de una metodología participativa, enfocada a escuchar más que imponer, la cual permitió finalmente contar con una delimitación (Espinoza 2016).

La idea de una tensión entre tradición y modernidad, reflejada en el patrimonio cultural no solamente en los términos de su significado simbólico para la comunidad o en términos de su uso tradicional del espacio, sino también en términos del reclamo de algunos actores que claman que el patrimonio entorpece el progreso y desarrollo. Paradójicamente, otros autores creen justamente todo lo contrario, es decir el patrimonio como la oportunidad de defender la tradición y hacerle frente al progreso. Así, se demuestra la poca representatividad del discurso académico en la interacción con el patrimonio que asume, veladamente, la oposición entre autoridad o grupo tradicional con los intentos de modernización del Estado.

Una línea adicional que demuestra los peligros de la sobre simplificación en bueno y malos o Estadocomuneros es el tema del turismo. El Qhapaq Ñan, es también una materialización de las tensiones entre Turismo y Cultura. Pese a que desde la academia ha sido plenamente demostrado que la actividad turística 
puede estar acompañada de muchas trasformaciones sociales nocivas para la comunidad, lo que es claro es que las comunidades, con razón o sin ella, generan expectativas hacia el turismo. Más allá de que para nosotros, como gestores patrimoniales, el turismo es solo instrumental y secundario, ¿en dónde radica nuestra autoridad como académicos para decir que las iniciativas turísticas son buenas o no, inclusive sobre los deseos y expectativas de las poblaciones locales?

El Qhapaq Nan, como todo el patrimonio, es la materialización de esas dinámicas sociales, es cambiante dependiendo cómo cambia la sociedad, está formado por las realidades y expectativas de varios actores compitiendo, no por el control del patrimonio, sino por el poder que puede formarse alrededor del mismo.

\section{De la Puesta Social a la Cogestión del Patrimonio Arqueológico}

Después de toda esta discusión sobre la concepción del patrimonio, las preguntas centrales continúan: ¿Cómo hacemos para construir una idea de patrimonio que sea más inclusiva, que tenga un marco conceptual, que nos permita analizar los usos del patrimonio más allá de los discursos patrimonialista clásicos de turismo e identidad (Smith 2006:44)? ¿Cómo generar transformaciones que vayan más allá de la denuncia o el cuestionamiento del discurso patrimonial clásico e involucren efectivamente a la población? ¿Cómo hacer para diferenciar el acuerdo de las poblaciones locales, con una participación real y activa en el gobierno y manejo del patrimonio? (Korstanje y García 2007; Perkin 2010).

En general, creemos que la construcción de las respuestas a estas preguntas debe pasar por pensar en tres ejes básicos de acción: (1) Soltar el poder y la autoridad sobre el patrimonio, incorporando versiones alternas de los discursos, así estas versiones entren en conflicto con las nuestras. Pero, sobre todo, perder la pretensión de que podemos llegar a hablar por el otro y dejarlo -efectivamente- hablar; inclusive, estar dispuestos a soportar que se cuestione nuestra legitimidad y autoridad como académicos o gestores culturales. (2) Reconocer una variabilidad de agentes y actores asociados al patrimonio, lo que empieza por reconocer las dinámicas locales alrededor del patrimonio que, probablemente, sobrepasan al patrimonio cultural per-se. Por ende, asumir que somos, como profesionales advocados a la gestión del mismo, mediadores y no proveedores de patrimonio (Perkin 2010:109). (3) Asegurar que todos los actores sean efectivamente convocados a usar el patrimonio y exponer sus posiciones disonantes (Harvey 2001; Perkin 2010).
Garantizar el flujo de información correcta y capacidad de decisión de los grupos usualmente dejados de lado a la hora de decidir cómo y para qué se va a gestionar determinado patrimonio.

\section{Desde la posición de agente patrimonial}

Entonces, ¿cómo hacemos para darle al Qhapaq Ñan un uso dinámico, que sirva para cuestionar las estructuras tradicionales de la nación peruana, sustentadas en la manipulación del patrimonio, sin perder de vista la importancia del mismo en las agendas locales? Al principio retomamos el concepto de Jallade (2011:12) de uso social, pero re-definiéndolo. Nuestra definición buscó una manera que hiciera al patrimonio activo y dinámico. Para nosotros, uso social se definió como: "un proceso dialógico y democrático que busca proteger, conservar y promover los bienes culturales materiales e inmateriales de manera participativa, buscando su reconstitución como elemento trascendente para el desarrollo sostenible de las comunidades" (Marcone y Ruiz 2014:119). Esta definición nos alejó inicialmente de los discursos tradicionalistas sobre el patrimonio, reconociendo el carácter social y contemporáneo del mismo, sobre el histórico/arqueológico. Sin embargo, puesto en esos términos generales, el uso social continuó siendo una política desde arriba. El ánimo de hacer un proyecto participativo puede terminar formalizando más el manejo desde arriba del patrimonio (Perkin 2010). Es quizás ahí donde muchas de las buenas intenciones de los planes iniciales del Qhapaq Ñan fallaron en su intento de hacerlo verdaderamente participativo, como señalan Jallade, Losson, Korstanje y García entre otros.

Concluimos que este uso social para ser realmente participativo tenía que tener como fin último la cogestión del patrimonio, donde todos los actores asuman y ejerzan sus derechos y responsabilidades. Es decir, esta cogestión implica:

(1) Generar procesos de diálogo para reconocer intereses comunes y llegar a consensos, donde las poblaciones tengan participación activa y real en la toma de decisiones. Así, integrar las expectativas y necesidades locales de mejoras de la calidad de vida en relación a visiones alternativas del patrimonio y su gestión (Marcone y Ruiz 2014:120). Aún lejos de implementarlo a nivel nacional, se han desarrollado iniciativas de planificación conjunta que incluyen la auto evaluación de las poblaciones; como las realizadas en el área de Aypate, Piura, cerca de la frontera con Ecuador. En la misma línea, se ha fomentado -a partir de una iniciativa del 
proyecto Qhapaq Ñan Bolivia (Morales y Camarena 2009)- una serie de talleres para fomentar la gestión de museos comunitarios como herramienta de apropiación social. Del mismo modo, se ha logrado la emisión de una serie de ordenanzas municipales que, si bien son mayoritariamente declarativas, establecen las responsabilidades de los gobiernos locales con el patrimonio.

(2) Desarrollar un proceso participativo de planificación para el desarrollo de acciones conjuntas, donde las comunidades y actores locales representativos se involucren (Marcone y Ruiz 2014:121). Por ejemplo, la realización del plan de manejo de Huaycán de Cieneguilla se convirtió en un instrumento de planificación, pero también de ordenamiento conjunto del territorio. Este permitió resolver problemas de acceso y límites con las poblaciones circundantes al sitio, basados en la convivencia y comunicación. Además, el caso de Huaycán de Cieneguilla es interesante en la medida que ejemplifica una convivencia ejemplar con la municipalidad, la cual se ha apropiado del Qhapaq Ñan y ha reconstruido sus procesos identitarios en función a este bien.

(3) Implementar un proceso de gestión concertada para el desarrollo sustentable, donde el patrimonio no es un fin, sino un instrumento que contribuye para el mejoramiento de la calidad de vida. Esto mediante el establecimiento de puentes y conexiones entre la comunidad y otras instituciones estatales, cooperantes internacionales y empresas productivas (Marcone y Ruiz 2014:121). Por ejemplo, más arriba de Cieneguilla, en la localidad de Nieve-Nieve, existe un tramo nominado como patrimonio mundial. Durante los trabajos de diagnóstico y conservación de este tramo surgió el problema del manejo de residuos sólidos que esta comunidad tiene. Entonces, a partir del proyecto Qhapaq Ñan nació una iniciativa con la comunidad para la cual se buscó al Ministerio del Ambiente del Perú y se desarrolló un plan de manejo adecuado de residuos sólidos en la localidad. Así, el acercamiento entre el Estado y las comunidades, de alguna manera, puede ser mediado por el Patrimonio.

En el mismo Huaycán de Cieneguilla, con la ayuda de la Sustanaible Preservation Initiative, se comenzó un proyecto productivo basado en la capacitación de una serie de artesanos peleteros asentados en la localidad. Esta población, migrante de Puno, empezó a construir su propia identidad como artesanos, a través de la apropiación de los símbolos patrimoniales en el distrito. El patrimonio les provee un medio de reconciliar su origen con su presente y sirve para fomentar la discusión sobre la identidad del distrito de manera más general.

El Qhapaq Ñan también ha servido como eje para una propuesta interestatal entre Bolivia, Perú y Ecuador de un plan de turismo rural comunitario basado en los atractivos turísticos patrimoniales, realizados con fondos de la cooperación italiana y en alianza con el PNUD. Si bien la población circundante aún es escéptica al plan y las acciones concretas están aún por desarrollarse, el proyecto ha servido para poner atención a la zona fronteriza en ambos lados del límite peruano y fomentar intercambios entre las comunidades de los tres países. Así, se realizó la III Caminata Regional y I Caminata Binacional Perú-Bolivia por el Gran Qhapaq Ñan en el tramo Chucasuyo Ccajje-Juli en el distrito de Juli, provincia de Chucuito, región de Puno, en junio del 2017. Esta contó con la participación activa de más de 2.000 personas entre comunidades, intelectuales y hasta alumnos universitarios. Más allá del impacto en términos de rentabilidad económica o turística de esta iniciativa de TRC, el proyecto ha fomentado la interacción de actores locales, a diferentes escalas, que antes no contaban con espacios de interacción. El turismo, así visto, es una herramienta de gestión social del patrimonio y no un fin.

(4) Generar una apropiación del patrimonio de tal manera que se reconstituyan sus significados a nivel local, fomentando la participación activa en su gestión. Para ello, hemos generado un fuerte programa educativo, donde si bien se imparten contenidos específicos fruto del trabajo académico, se trata de evitar asumir determinado valor/significado predeterminado del patrimonio como el mejor y mucho menos imponerlo. Más bien, se busca fomentar la creación de nuevos significados, que estarán de acuerdo a las expectativas locales.

Sin embargo, es importante ser críticos con el proceso. Este es lento, ya que involucra negociaciones horizontales entre comunidades y representantes estatales, se ve dificultado por agentes patrimoniales que conservan visiones patrimoniales clásicas sobre cómo debe ser gestionado el patrimonio, pero también por un aparente desinterés de la gente. Es ahí donde el proceso de apropiación y conversación es fundamental. No solo hemos fallado en revelar la importancia del patrimonio para sus vidas, sino que este fue el mecanismo que permitió enajenarlo de su contexto local.

\section{A Manera de Conclusión}

La diversidad y extensión del Qhapaq Ñan en el territorio peruano nos permite determinar que el patrimonio no es un discurso único y uniforme. La relación entre el Estado y los diversos actores que rodean el patrimonio tampoco es única o invariable. Las poblaciones locales tienen discursos cambiantes y ambivalentes con respecto al patrimonio; $y$, dependiendo 
de sus agendas e intereses, estos pueden ser muy críticos o totalmente proactivos. Cada actor es un caso por sí mismo.

Simplificar el problema del patrimonio dentro un esquema dicotómico Estado versus comuneros o elites criollas versus indígenas, solo termina por recrear el problema de ver el patrimonio como objeto. Pero esta vez, el discurso autorizado no es el histórico, creado desde la burocracia oficial, sino el de la actitud hipercrítica y la pretensión académica de hablar por el otro, como si el otro no tuviera voz. Como se demuestra en los ejemplos discutidos en el presente trabajo, las poblaciones tienen una relación ambivalente y cambiante con el patrimonio.

El Qhapaq Ñan, como todo patrimonio es un proceso, cambiante y complejo donde se articula también una larga historia de manipulación del patrimonio. Esta larga tradición patrimonial en el Perú no puede ser negada y ha sido usada como materia prima para justificar discursos nacionales excluyentes. Estos discursos son parte de la historia, de la memoria colectiva y de cómo se construyó nuestra sociedad; negar esto es simplemente tapar el sol con un dedo. El patrimonio, hoy por hoy no es una invención estatal, sino una permanente presencia en todos los habitantes del Perú, indígenas o criollos.

Finalmente, el patrimonio puede cuestionar, en su fibra más profunda, los esquemas mentales excluyentes imperantes en la nación peruana. El Qhapaq Ñan representa una oportunidad para cuestionar la historia oficial, revalorar las continuidades y la ocupación local, recuperar -al menos conceptualmente- el componente cultural del territorio y fomentar el dialogo entre el Estado y los diversos actores sociales. En una frase, el patrimonio es el insumo por donde empezar la verdadera transformación social. Pero para esto, los profesionales debemos abandonar los estereotipos y pretensiones académicas y sobre todo la condescendencia. Debemos perder poder y autoridad sobre la gente, dejarla expresar sus deseos y expectativas, para así lograr que se involucren directamente con el patrimonio y lo usen para su beneficio.

Agradecimientos: Necesito reconocer y agradecer a Gabriela García Benavente por todo el apoyo para la realización de este artículo, también a Maria Luisa Rendon y a Jorge Marcone, por sus comentarios a las versiones tempranas del artículo. Finalmente agradecer a todos mis compañeros del Proyecto Qhapaq Ñan del Ministerio de Cultura con quienes seguimos pensando que el patrimonio es un motor de cambio social. Quiero agradecer especialmente a los editores de la revista Chungara, por invitarme a convertir este trabajo de reflexión en un artículo de debate, que espero contribuya a examinar y cuestionar la formas como pensamos la gestión del patrimonio cultural en nuestros países.

\section{Referencias Citadas}

Asensio, R.H. 2014. ¿De qué hablamos cuando hablamos de participación comunitaria en la gestión del patrimonio cultural. Revista Argumentos 7 (3):25-33.

de Cieza de León, P. 1985. Obras Completas II. Madrid.

Espinoza, O. 2016. Delimitar no es excluir: El caso del saneamiento físico-legal de la zona arqueológica de Vilcas Huamán, Ayacucho. 16 de Diciembre. http://qhapaqnan.cultura.pe/sites/default/files/ articulos/Delimitar\%20no\%20es\%20excluir.pdf (25 junio 2017)

Giddens, A. 1984. The Constitution of Society: Outline of the Theory of Structuration. Polity Press, Cambridge.

Gnecco, C. 2017. Obsesión por las ruinas...y la ruina del Qhapaq Ñan. El Malpensante 182:54-59.

Harvey, D.C. 2001. Heritage pasts and heritage presents: Temporality, meaning and the scope of heritage studies. International Journal of Heritage Studies 7 (4):319-338.

Harvey, D.C. 2015. Heritage and scale: setting, boundaries and relations. International Journal of Heritage Studies 21 (6):577593.

Jallade, S. 2011. La réinvention des routes incas: représentations et construction de la mémoire au Pérou (2001-2011), Droit et cultures [En Linea], 62 | 2011-2, subido en 04 mayo 2012, consultado 14 junio 2019. URL : http://journals.openedition.org/ droitcultures/2663.
Joseph, S. 2004. Political Theory and Power. Foundations Books, New Delhi.

Korstanje, M.A. y J. García Ascárate 2007. The Qhapaq Nan Project: A Critical View. Archaelogies: Journal of the World Archaelogical Congress 3 (2):116-131.

Losson, P. 2017. The inscription of Qhapaq Nan on UNESCO's World Heritage List: A comparative perspective from the daily press in six Latin American countries. International Journal of Heritage Studies 23 ( 6):521-537.

Lowenthal, D. 1998. The Heritage Crusade and the Spoils of History. Cambridge Univerisity Press, Cambridge.

Marcone, G. 2011. Más Inca que los Incas. Cuaderno de investigación del archivo Tello \#8:11-15. Museo de Arqueología y Antropología de la Universidad Nacional Mayor de San Marcos, Lima.

Marcone, G. y R. Ruiz. 2014. Qhapaq Ñan: el reto del uso social del patrimonio cultural. Edición Quehacer 195:114-121.

Méndez, C. 1996. Incas sí, indios no: Notes on Peruvian creole nationalism and its contemporary crisis. Journal of Latin American Studies 1 (28):197-225.

Morales, T. y C. Camarena 2009. Manual para la Creación y Desarrollo de Museos Comunitarios. Fundación Interamericana de Cultura y Desarrollo, La Paz. 
Ortner, S.B. 2006. Anthropology and Social Theory. Culture, Power and the acting subject. Duke University Press, Durham.

Perkin, C. 2010. Beyond the rhetoric: negotiating the politics and realising the potential of community-driven heritage engagement. International Journal of Heritage Studies 16 (1-2):107-122.
Smith, L. 2006. Uses of Heritage. Routledge, London.

Tilley, C. y D. Miller. 1984. Ideology, Power and Prehistory: an Introduction. En Ideology, Power and Prehistory, editado por D. Miller y C. Tilley, pp. 1-10. Cambridge University Press, Cambridge.

Waterton, E. 2010. Politics, Policy and the Discourses of Heritage in Britain. Palgrave Macmillan, London. 
